${ }^{1}$ Department of Pediatrics, Cardiology unit, Cairo University, Cairo, Egypt ${ }^{2}$ Center for Social and Preventive Medicine, Cairo University, Cairo, Egypt

*Email:

wessamsaleem@rocketmail.com http://dx.doi.org/ 10.21542/gcsp.2017.27

Received: 12 September 2017 Accepted: 8 November 2017 (C) 2017 The Author(s), licensee Magdi Yacoub Institute. This is an open access article distributed under the terms of the Creative Commons Attribution license CC BY-4.0, which permits unrestricted use, distribution and reproduction in any medium, provided the original work is properly cited.
Case study

\section{Acute Kawasaki disease with emphasis on the echocardiographic profile: A single center experience}

\author{
Hala S. Hamza ${ }^{1}$, Wessam A. Raouf² , Asmaa Z. Zaher², Hala M. Agha
}

\begin{abstract}
Background: Echocardiographic features of acute Kawasaki disease (KD) have not been well characterized in Egyptian children. This study aimed to provide insight into the pattern of cardiac involvement in Egyptian children with Kawasaki disease, focusing on echocardiographic coronary abnormalities and their associated risk predictors.
\end{abstract}

Methods and Results: Medical records of 64 KD patients from 2012 to 2016 were retrospectively analyzed with recalculation of coronary artery z-scores during the first eight weeks after fever onset. All patients received intravenous immunoglobulin (IVIG) and $57.8 \%$ were treated within 10 days of illness onset. Coronary abnormalities were found in $53.1 \%$ of all patients, and in $43.2 \%$ of those who received IVIG within 10 days. Giant aneurysms (z-score>10) comprised $23.5 \%$ of all coronary abnormalities. Coronary thrombosis occurred in two patients $(5 \%)$, both of whom developed myocardial infarction, and one succumbed to heart failure with eventual in-hospital death. Overall, $7 \%$ of patients had mitral regurgitation $(n=5), 1.5 \%$ had aortic regurgitation $(n=1)$, and $7.8 \%$ had pericardial effusion $(n=5)$. Among a number of laboratory and clinical predictors, platelet count had the strongest association with coronary abnormalities (Area under Receiver-operating characteristic (ROC) curve: 0.794; 95\% confidence interval 0.678-0.910; $P<0.001$ ).

Conclusion: Coronary abnormalities occur in a substantial percentage of KD in Egypt, with associated evidence of severe inflammation. Further efforts are required to increase awareness of the disease and to emphasize the importance of early IVIG administration. Future studies should also be undertaken to characterize the long term progression profile of the disease as well as the possible genetic background of the disease in Egypt. 


\section{BACKGROUND}

Echocardiography has a key role in the diagnosis, risk stratification and management of patients with Kawasaki disease (KD). ${ }^{1-3}$ Coronary vasculitis, pericarditis, endocarditis and myocarditis can all be encountered upon echocardiographic evaluation in the acute phase of KD. However, coronary involvement appears to have the most detrimental sequelae. 2,4,5 The American Heart Association (AHA) recommends periodic echocardiographic assessment at the time of diagnosis, at 2 weeks after diagnosis, and at 6-8 weeks, which covers the highest risk period when coronary dilatation, hypercoagulability, and mortality all peak. ${ }^{1,2}$

Coronary abnormalities had been reported in $15 \%$ to $25 \%$ of children not receiving IVIG, and in $2-6 \%$ of those who received IVIG within 10 days of illness. ${ }^{1-3}$

The coronary and cardiac involvement profile of KD in Egyptian children has not been well characterized. This study sought to describe the echocardiographic pattern of acute $\mathrm{KD}$ in a large Egyptian pediatric center.

\section{PATIENTS AND METHODS}

\section{Patient selection}

Medical records of patients diagnosed with KD at the Children's Hospital of Cairo University, between 2012 and 2016 were retrospectively reviewed. Patients meeting the AHA criteria for KD, who had echocardiographic evaluation within the first eight weeks of fever were included. ${ }^{1}$ The study was in line with the institutional ethical policy. Demographic data, clinical features, laboratory results and echocardiographic findings were analyzed. Z-scores for the right coronary artery (RCA), the left anterior descending coronary artery $(L A D)$, and the left main coronary artery ( $L M C A)$ were retrospectively calculated using coronary artery internal dimensions and patient's body surface area measured at the time of the echocardiographic study showing the largest coronary dimensions. ${ }^{6,7}$

Coronary artery dilatation was considered present when any coronary segment exceeded a z-score of 2.5. ${ }^{1}$ Dilatation was classified as small if the z-score was between 2.5 and 5 , large between 5 and 10 , and giant if more than 10. ${ }^{8}$ Patients were then divided into two groups according to the presence of coronary abnormalities.

\section{Statistical analysis}

Variables were expressed as means with standard deviations (SD), medians with interquartile range (IQR), or counts with percentages, as appropriate. Student t- test or Mann-Whitney $U$ test were used for comparison between groups. Fisher's exact test and chi-square test were used to compare proportions. Univariable factors that were significantly associated with coronary involvement were included in a multivariate logistic regression analysis to identify variables which were independently associated with coronary involvement. Receiver-operating characteristic (ROC) curve analysis was then employed to determine the area under the curve (AUC) for each significant predictor. Spearman test was used to assess correlations. P values of $<0.05$ were considered significant. Statistical analysis was performed using the commercially available software IBM SPSS Statistics for Windows (version 19.0. Armonk, NY).

\section{RESULTS}

Of 85 patients identified by searching the hospital database, 21 were excluded due to incomplete data (Figure 1). The study population comprised of 64 patients, including 


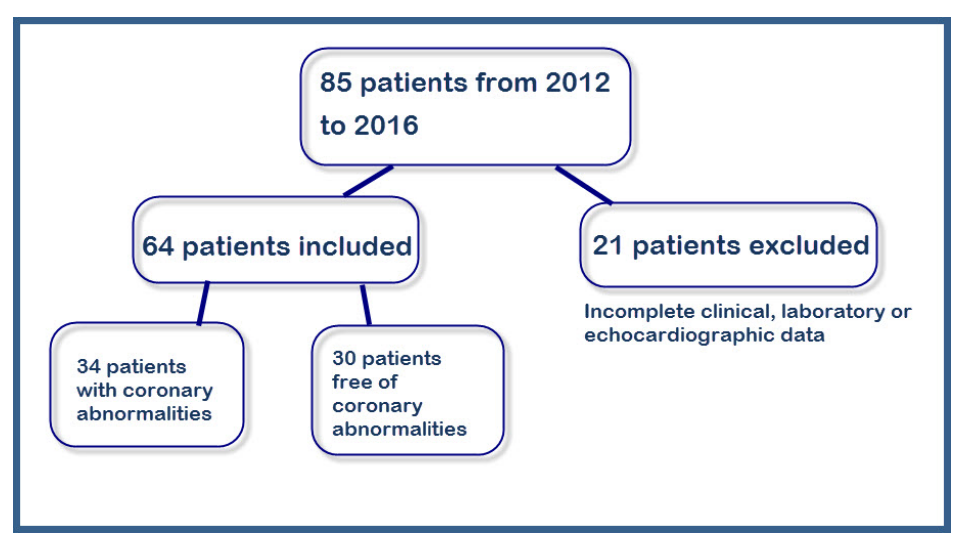

Figure 1. Patient selection.

23 females (35.9\%). All patients had no previous attacks of KD and all received IVIG $(2 \mathrm{~g} / \mathrm{kg})$ with $37(57.8 \%)$ treated within the first 10 days. Five patients received IVIG after the fever had subsided due to either limited access to IVIG where they had been initially diagnosed or delayed search for medical consultation. Coronary arterial lesions were detected in $34 / 64$ (53.1\%) of all patients and in 16/37 (43.2\%) of those who received IVIG within 10 days.

Coronary abnormalities included small coronary aneurysms in 13 (38.2\% of all coronary lesions), large coronary aneurysms in 13 (38.2\%), giant coronary aneurysms in eight (23.5\%). Coronary thrombi were identified in two patients (5\% of all coronary abnormalities) with giant aneurysms; both had myocardial infarction, one of them developed depressed myocardial function (shortening fraction: 13.4\%) and died inhospital. None of the patients had coronary stenosis in the acute stage.

The LAD was most commonly affected in $64.7 \%$ of patients with coronary involvement, followed by the RCA in $55.8 \%$ and the LMCA in $38.2 \%$ (Table 1). Measurements of the circumflex artery were not included due to lack of normative values in the z-score calculator used for the current study; however, circumflex dilatation (luminal diameter >3 $\mathrm{mm}$ in children less than 5 years old, or > $4 \mathrm{~mm}$ in children older than 5 years old) ${ }^{9}$ was reported only in two patients who had coexisting LAD and LMCA dilatation. Valve lesions were exclusively found in patients with coronary involvement. Five patients had mitral regurgitation and only one patient had aortic regurgitation. Valvular lesions were mild in degree in all patients except one who had severe mitral regurgitation associated with LMCA and LAD coronary thrombosis and myocardial infarction. Small

Table 1 The range of coronary abnormalities.

\begin{tabular}{llll}
\hline & $\begin{array}{l}\text { Right Coronary } \\
\text { Artery }(\boldsymbol{n = 1 9 )})\end{array}$ & $\begin{array}{l}\text { Left Main Coronary } \\
\text { Artery }(\boldsymbol{n = 1 3})\end{array}$ & $\begin{array}{l}\text { Left Anterior Descending } \\
\text { Artery }(\boldsymbol{n = 2 2})\end{array}$ \\
\hline $\begin{array}{l}\text { Patients with isolated } \\
\text { involvement (n) }\end{array}$ & $8(42.1 \%)$ & $3(23.07 \%)$ & $9(40.9 \%)$ \\
Patients with z-score: $2.5-5(\mathrm{n})$ & $8(42.1 \%)$ & $8(61.5 \%)$ & $8(36.36 \%)$ \\
Patients with z-score: 5 -10 (n) & $6(31.5 \%)$ & $4(30.7 \%)$ & $8(36.36 \%)$ \\
Patients with z-score >10 (n) & $5(26.3 \%)$ & $1(7.6 \%)$ & $6(27.27 \%)$ \\
Thrombus (n) & 1 & 1 & 2 \\
Diffuse Ectasia (n) & 2 & 1 & 1 \\
\hline
\end{tabular}


pericardial effusion was found in five patients, three with coronary abnormalities and two with normal coronaries. Left ventricular indexed dimensions and fractional shortening were not significantly different between patients with or without coronary involvement (Tables 2 and 3). Compared with patients who had no coronary involvement, those with coronary abnormalities had significantly lower hematocrit and hemoglobin levels, higher erythrocyte sedimentation rate (ESR), total leukocyte and platelet counts, longer duration of fever, and more delayed administration of IVIG.

Table 2 Clinical criteria of Kawasaki disease patients with and without coronary abnormalities. Data presented as: number (percentage).

\begin{tabular}{lll}
\hline & $\begin{array}{l}\text { Patients with coronary } \\
\text { abnormalities }(\boldsymbol{n = 3 4 )}\end{array}$ & $\begin{array}{l}\text { Patients without coronary } \\
\text { abnormalities }(\boldsymbol{n}=\mathbf{3 0})\end{array}$ \\
\hline Exanthema (n) & $24(70.5 \%)$ & $20(66.6 \%)$ \\
Conjunctival injection (n) & $26(76.4 \%)$ & $27(90 \%)$ \\
Changes in Extremities (n) & $23(67.6 \%)$ & $30(100 \%)$ \\
Cervical Lymphadenopathy (n) & $25(73.5 \%)$ & $24(80 \%)$ \\
Lips \& Oral Changes (n) & $23(67.6 \%)$ & $25(83.3 \%)$ \\
Refractory KD (n) & $4(11.7 \%)$ & $3(10 \%)$ \\
Complete KD (n) & $23(67.6 \%)$ & $30(100 \%)$ \\
\hline
\end{tabular}

Table 3 Characteristics of patients with and without coronary abnormalities. A $P$ value of $<0.05$ was considered significant.

\begin{tabular}{|c|c|c|c|}
\hline & $\begin{array}{l}\text { Patients with coronary } \\
\text { abnormalities }(n=34)\end{array}$ & $\begin{array}{l}\text { Patients without coronary } \\
\text { abnormalities }(n=30)\end{array}$ & $\boldsymbol{P}$-values \\
\hline Age (years) ${ }^{a}$ & $3(1.5-6)$ & $3.25(2-5)$ & 0.840 \\
\hline Females $(n)^{b}$ & $10(29.4 \%)$ & $13(43.3 \%)$ & 0.160 \\
\hline Body surface area $\left(\mathrm{m}^{2}\right)^{a}$ & $0.61(0.48-0.74)$ & $0.66(0.49-0.74)$ & 0.466 \\
\hline Days of fever $(n)^{a}$ & $14(9.5-15)$ & $7(7-12.5)$ & 0.008 \\
\hline Days at IVIG administration (n) ${ }^{a}$ & $12(7.75-15.25)$ & $7(5-12.5)$ & 0.006 \\
\hline Hemoglobin $(g / d l)^{a}$ & $9.35(8.6-11)$ & $11(10-12.1)$ & 0.007 \\
\hline Hematocrit (\%) ${ }^{\mathrm{a}}$ & $29.95(27-31.85)$ & $32(31.1-32.25)$ & 0.004 \\
\hline $\operatorname{PLC}\left(\times 10^{3} / \mathrm{mm}^{3}\right)^{\mathrm{a}}$ & $570.5(445.5-707.5)$ & $301(250.7-506)$ & $<0.001$ \\
\hline $\mathrm{ESR}(\mathrm{mm} / \text { hour })^{\mathrm{a}}$ & $104.5(94.5-120)$ & $60(53-110)$ & 0.010 \\
\hline $\operatorname{TLC}\left(\times 10^{3} / \mathrm{mm}^{3}\right)^{\mathrm{a}}$ & $11.5(9.6-15)$ & $8.2(6-12.9)$ & 0.021 \\
\hline Pericardial Effusion ${ }^{b}$ & $3(8 \%)$ & $2(6 \%)$ & \\
\hline Mitral/Aortic Regurgitation ${ }^{\mathrm{b}}$ & $6(17 \%)$ & 0 & \\
\hline LVEDDI $\left(\mathrm{mm} / \mathrm{m}^{2}\right)^{\mathrm{c}}$ & $58.2 \pm 15.13$ & $52.4 \pm 11.3$ & 0.056 \\
\hline LVESDI $\left(\mathrm{mm} / \mathrm{m}^{2}\right)^{\mathrm{c}}$ & $35.5 \pm 11.47$ & $31.1 \pm 7.9$ & 0.071 \\
\hline LVFS $^{\mathrm{c}}{ }^{\mathrm{C}}$ & $39.2 \pm 0.08$ & $40.7 \pm 6(29-54)$ & 0.580 \\
\hline
\end{tabular}

Notes.

${ }^{a}$ median (interquartile range).

${ }^{b}$ number (percentage).

${ }^{c}$ mean \pm standard deviations.

ESR, erythrocyte sedimentation rate; IVIG, intravenous immunoglobulin; LVEDDI, left-ventricular end-diastolic dimension index; LVESDI, left-ventricular end-systolic dimension index; LVFS, left-ventricular fractional shortening; PLC, platelet count; TLC, total leukocyte count. 
Among all these variables, platelet count (PLC) performed as the best predictor of coronary involvement (Table 4), (AUC: 0.794; 95\% confidence interval 0.678-0.910; $P<0.001)$. Positive correlations were statistically significant between all three individual coronary artery z-scores and day of illness at IVIG administration, ESR, and platelet count. A significant negative correlation was found with hemoglobin level (Table 5).

\section{DISCUSSION}

The current study reported more males affected with Kawasaki disease than females, the male:female ratio in the current study was 1.78:1, in keeping with the common male gender predilection found in several studies. ${ }^{2,10,11}$

Echocardiographic abnormalities of the coronary arteries were observed in 53.1\% of all patients. This high rate may be only partially accounted for by the relatively

Table 4 Multivariate analysis of factors associated with coronary abnormalities.

\begin{tabular}{llll}
\hline & Odds Ratio & $\begin{array}{l}\text { 95\% confidence } \\
\text { interval }\end{array}$ & P-value \\
\hline Hematocrit & 0.904 & $0.611-1.336$ & 0.612 \\
Hemoglobin & 1.004 & $0.437-2.306$ & 0.992 \\
Total leukocytic count & 1.068 & $0.907-1.257$ & 0.429 \\
Platelet count & 1.004 & $1.000-1.008$ & 0.035 \\
Duration of fever & 0.995 & $0.872-1.136$ & 0.944 \\
Intavenous Immunoglobulin & 1.016 & $0.884-1.168$ & 0.821 \\
administration day & & & \\
Erythrocyte sedimentation rate & 1.007 & $0.987-1.028$ & 0.480 \\
Presence of refractory Kawasaki & 0.361 & $0.015-8.823$ & 0.532 \\
\hline
\end{tabular}

Table 5 Correlations between different parameters and coronary z-scores. A $P$ value of $<0.05$ was considered significant.

\begin{tabular}{|c|c|c|c|}
\hline & z-scores for the LAD & z-scores for the LMCA & z-scores for the RCA \\
\hline \multirow[t]{2}{*}{ Days of fever (n) } & $r: 0.162$ & $r: 0.303$ & r:0.431 \\
\hline & P:0.200 & P:0.015 & $P<0.001$ \\
\hline \multirow{2}{*}{$\begin{array}{l}\text { Days at IVIG } \\
\text { administration (n) }\end{array}$} & $r: 0.327$ & $r: 0.351$ & $r: 0.356$ \\
\hline & $P: 0.008$ & $P: 0.004$ & P:0.004 \\
\hline \multirow{2}{*}{ Hemoglobin (g/dl) } & $r:-0.423$ & $r:-0.369$ & $r:-0.262$ \\
\hline & $P: 0.001$ & P:0.003 & $P: 0.036$ \\
\hline \multirow[t]{2}{*}{ Hematocrit (\%) } & $r:-0.459$ & $r:-0.459$ & $r:-0.239$ \\
\hline & $P<0.001$ & $P<0.001$ & $P: 0.057$ \\
\hline \multirow[t]{2}{*}{$\operatorname{PLC}\left(\times 10^{3} / \mathrm{mm}^{3}\right)$} & $\mathrm{r}: 0.516$ & r:0.386 & $r: 0.392$ \\
\hline & $P<0.001$ & P:0.002 & P:0.001 \\
\hline \multirow[t]{2}{*}{ ESR (mm/hour) } & $r: 0.406$ & $r: 0.364$ & $r: 0.268$ \\
\hline & $P: 0.001$ & P:0.003 & P:0.033 \\
\hline \multirow[t]{2}{*}{$\operatorname{TLC}\left(\times 10^{3} / \mathrm{mm}^{3}\right)$} & $r: 0.364$ & $r: 0.163$ & $r: 0.142$ \\
\hline & $P: 0.003$ & P:0.199 & $P: 0.262$ \\
\hline
\end{tabular}

Notes.

ESR, erythrocyte sedimentation rate; IVIG, intravenous immunoglobulins; PLC, platelets count; TLC, total leukocytic count. 
delayed administration of IVIG, because it is even higher than that previously reported in patients not receiving IVIG within 10 days in many countries. ${ }^{10,12-14}$ Moreover, even in the subgroup of patients who received IVIG within 10 days after fever onset, 43.2\% had z-scores $>2.5$. This is contrary to the observations of other researchers who reported

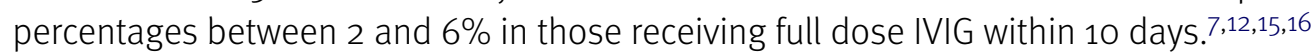
This raises the possibility of an ethnic or a genetic factor among Egyptian children that may predispose to worse outcomes.

Zhang and colleagues also reported coronary involvement in $63.3 \%$ of their cohort of patients. ${ }^{17}$ Similar to other studies, the current study found the LAD to be the most commonly involved artery followed by the RCA then the LMCA. ${ }^{2,3}$ Other researchers found a predilection for the LMCA or equal involvement of the RCA and the LAD. ${ }^{14,18}$

Many studies sought to identify criteria associated with higher risk of coronary abnormalities, and accordingly many laboratory, demographic and clinical parameters have been suggested to predict which KD patients at higher risk for severe vasculitis and coronary artery aneurysms.1,12,19,20 This was of more importance before the establishment of IVIG as a standard therapy for all KD patients., ${ }^{1,20}$ However, in regions with limited resources an attempt at risk stratification may be of value, especially to determine the frequency of echocardiographic studies needed, to ensure early IVIG administration, and to consider the use of newer immunomodulatory agents. ${ }^{21}$

In the current study, and in contrast to other studies, age, body surface area, male or female sex, and IVIG refractoriness were not found to be significantly associated with coronary abnormalities., ${ }^{7,22-25}$ On the other hand, ESR, platelet count, leukocyte count, hemoglobin, hematocrit, duration of fever, and the day of IVIG administration showed significant association with coronary abnormalities. Similar findings for one or more of these parameters have been reported by other researchers. ${ }^{20,22,24,26,27}$ High platelet count had the strongest association and predictive power for coronary abnormalities. Thrombocytosis showed significant association with coronary abnormalities and indicated more severe vasculitis according to other reports. ${ }^{20,22,28,29}$

\section{LIMITATIONS}

The relatively small sample size precludes extrapolation of the findings to the general Egyptian population. Retrospective evaluation of echocardiographic measurements carries a high risk of inconsistent methodology. Many laboratory tests that had been shown to predict coronary abnormalities were not included in the analysis because they were not obtained in many patients (e.g., C-reactive protein, serum albumin, hepatic enzymes).

\section{CONCLUSION}

This study describes the echocardiographic findings of acute KD in the understudied Egyptian population and highlights the elevated rate of coronary abnormalities. Despite the broad adoption of IVIG treatment in recent years, many patients still experienced delayed administration of IVIG, emphasizing the need for a nation-wide program for early recognition and treatment of KD in Egypt. A genetic variation unique to the Egyptian population should be also sought in the future. In addition, a larger follow-up study to further characterize progression and regression of coronary lesions should be performed. 


\section{FINANCIAL SUPPORT}

This research received no specific grant from any funding agency, commercial or not-forprofit sectors.

\section{CONFLICTS OF INTEREST}

None.

\section{REFERENCES}

[1] McCrindle BW, Rowley AH, Newburger JW, Burns JC, Bolger AF, Gewitz M, Baker AL, Jackson MA, Takahashi M, Shah PB, Kobayashi T, Wu M-H, Saji T, Pahl E. Diagnosis, treatment, and long-term management of Kawasaki disease: A scientific statement for health professionals from the American Heart Association. Circulation. 2017;135(17):e927-e999. doi: 10.1161/CIR.0000000000000484.

[2] Newburger JW, Takahashi M, Burns JC. Kawasaki disease. J Am Coll Cardiol. 2016;67(14):1738-1749. doi: 10.1016/j.jacc.2015.12.073.

[3] Friedman KG, Gauvreau K, Hamaoka-Okamoto A, Tang A, Berry E, Tremoulet AH, Mahavadi VS, Baker A, deFerranti SD, Fulton DR, Burns JC, Newburger JW. Coronary artery aneurysms in Kawasaki disease: Risk factors for progressive disease and adverse cardiac events in the US population. J Am Heart Assoc. 2016;5:e003289.

[4] Alonso-Gonzalez R, Wei-Li. Diastolic dysfunction in patients with Kawasaki disease. Int J Cardiol. 2010;145(3):520-521.

[5] Leonardi B, Giglio V, Sanders SP, Pasceri V, De Zorzi A. Ultrasound tissue characterization of the myocardium in patients after Kawasaki disease. Pediatr Cardiol. 2010;31:766-772.

[6] De Zorzi A, Colan SD, Gauvreau K, Baker AL, Sundel RP, Newburger JW. Coronary artery dimensions may be misclassified as normal in Kawasaki disease. J Pediatr. 1998;133:254-258.

[7] McCrindle BW, Li JS, Minich LL, Colan SD, Atz AM, Takahashi M, Vetter VL, Gersony WM, Mitchell PD, Newburger JW, Pediatric Heart Network Investigators. Coronary artery involvement in children with Kawasaki disease: Risk factors from analysis of serial normalized measurements. Circulation. 2007;116:174-179.

[8] Manlhiot C, Millar K, Golding F, McCrindle BW. Improved classification of coronary artery abnormalities based only on coronary artery z-scores after Kawasaki disease. Pediatr Cardiol. 2010;31:242-249.

[9] Research Committee on Kawasaki Disease. Report of subcommittee on standardization of diagnostic criteria and reporting of coronary artery lesions in Kawasaki disease. Tokyo, Japan: Japanese Ministry of Health and Welfare; 1984.

[10] Suzuki A, Tizard EJ, Gooch V, Dillon MJ, Haworth SG. Kawasaki disease: Echocardiographic features in 91 cases presenting in the United Kingdom. Arch Dis in Child. 1990;65:1142-1146.

[11] Saundankar J, Yim D, Itotoh B, Payne R, Maslin K, Jape G, Ramsay J, Kothari D, Cheng A, Burgner D. The epidemiology and clinical features of Kawasaki disease in Australia. Pediatrics. 2014;133:e1009-e1014.

[12] Beiser AS, Takahashi M, Baker AL, Sundel RP, Newburger JW. A predictive instrument for coronary artery aneurysms in Kawasaki disease. Am J Cardiol. 1998;81:1116-1120.

[13] Makino N, Nakamura Y, Yashiro M, Ae R, Tsuboi S, Aoyama Y, Kojo T, Uehara R, Kotani K, Yanagawa H. Descriptive epidemiology of Kawasaki disease in Japan, 2011-2012: From the results of the 22nd nationwide survey. J Epidemiol. 2015;25:239-245.

[14] Terai M, Shulman ST. Prevalence of coronary artery abnormalities in Kawasaki disease is highly dependent on gamma globulin dose but independent of salicylate dose. J Pediatr. 1997;131:888-893.

[15] Alexopoulos A, Vekiou A, Lycopoulou L, Tavena A, Lagona E, Kakourou T. Kawasaki disease in Greek children: A retrospective study. J Eur Acad Dermatol Venereol. 2013;27:580-588.

[16] Akhtar S, Alam MM, Ahmed MA. Cardiac involvement in Kawasaki disease in Pakistani children. Ann Pediatr Cardiol. 2012;5:129-132.

[17] Zhang X, Zhang Z, Liu S, Sun J. Epidemiologic survey of Kawasaki disease in Jilin from 1999 through 2008. Pediatr Cardiol. 2012;33:272-279.

[18] Rizk SR, El Said G, Daniels LB, Burns JC, El Said H, Sorour KA, Gharib S, Gordon JB. Acute myocardial ischemia in adults secondary to missed Kawasaki disease in childhood. Am J Cardiol. 2015;115:423-427.

[19] Ishihara H, Izumida N, Hosaki J. Criterion for early prediction of coronary artery involvement by clinical manifestations in patients with Kawasaki disease. Bull Tokyo Med Dent. 1985;32:77-89.

[20] Ghelani SJ, Kwatra NS, Spurney CF. Can coronary artery involvement in Kawasaki disease be predicted? Diagnostics. 2013;3:232-243.

[21] Rigante D, Andreozzi L, Fastiggi M, Bracci B, Natale MF, Esposito S. Critical overview of the risk scoring systems to predict non-responsiveness to intravenous immunoglobulin in Kawasaki syndrome. Int J Mol Sci. 2016;17: pii: E278.

[22] Harada K. Intravenous gamma-globulin treatment in Kawasaki disease. Acta Paediatr Jpn. 1991;33:805-810.

[23] Dominguez SR, Friedman K, Seewald R, Anderson MS, Willis L, Glodé MP. Kawasaki disease in a pediatric intensive care unit: A case-control study. Pediatrics. 2008;122:e786. 
[24] Giannouli G, Tzoumaka-Bakoula C, Kopsidas I, Papadogeorgou P, Chrousos GP, Michos A. Epidemiology and risk factors for coronary artery abnormalities in children with complete and incomplete Kawasaki disease during a 10-year. Pediatr Cardiol. 2013;34:1476-1481.

[25] Belay ED, Maddox RA, Holman RC, Curns AT, Ballah K, Schonberger LB. Kawasaki syndrome and risk factors for coronary artery abnormalities. Pediatr Infect Dis J. 2006;25:245-249.

[26] Kim T, Choi W, Woo C-W, Choi B, Lee J, Lee K, Son C, Lee J. Predictive risk factors for coronary artery abnormalities in Kawasaki disease. Eur J Pediatr. 2007;166:421-425.

[27] Morikawa Y, Ohashi Y, Harada K, Asai T, Okawa S, Nagashima M, Katoh T, Baba K, Furosho K, Okuni M, Ohano M. A multicenter, randomized, controlled trial of intravenous gamma globulin therapy in children with acute Kawasaki disease. Acta Pediatr Jpn. 1994;36:347-354.

[28] Chen J, Liu Y, Liu W, Wu Z. A meta-analysis of the biomarkers associated with coronary artery lesions secondary to Kawasaki disease in Chinese children. J Huazhong Univ Sci Technol. 2011;31:705-711.

[29] Weng K-P, Hsieh K-S, Huang S-H, Ou S-F, Ma C-Y, Ho T-Y, Lai C-R, Ger L-P. Clinical relevance of the risk factors for coronary artery lesions in Kawasaki disease. Kaohsiung J Med Sci. 2012;28:23-29. 